\title{
Characterization of Cryptocaryon irritans, a parasite isolated from marine fishes in Taiwan
}

\author{
Apolinario V. Yambot ${ }^{1}$, Yen-Ling Song ${ }^{1, *}$, Hung-Hung Sung ${ }^{2}$ \\ ${ }^{1}$ Department of Zoology, National Taiwan University, Taipei 106, Taiwan, ROC \\ ${ }^{2}$ Department of Microbiology, Soochow University, Taipei 106, Taiwan, ROC
}

\begin{abstract}
The ciliated protozoan parasite Cryptocaryon irritans infecting marine fishes in Taiwan is described. Developmental characteristics and sequences of the ribosomal DNA regions such as part of $18 \mathrm{~S}$, the entire first internal transcribed spacer, and part of $5.8 \mathrm{~S}$ of various Taiwan isolates of C. irritans were investigated. A total of 5 isolates was obtained from different fish-host species and localities, the majority from cultured fish species. C. irritans from Taiwan is able to shift its developmental characteristics, i.e. from non-adherent to adherent tomonts, from individualistic to aggregateforming tomonts, from infection of the gills only to infection of the gills and body. Thus, it is not possible to classify strains of $C$. irritans on the basis of these parameters. Premature tomonts that developed from dead fishes were able to produce theronts that could infect fish host. Isolates from Pingtung and the USA had identical nucleotide sequences while an isolate from Malaysia was identical to an Israel isolate. Percentage variation among pairs of Taiwan isolates showed a higher degree of variation than isolate sequences listed in GenBank. Sequence analysis revealed highly aberrant isolates in Taiwan, and a phylogenetic tree distinguished a marine and a low-salinity variant. C. irritans from marine fishes in Taiwan, therefore, display some characteristics not previously reported. Since manipulation of salinity in brackishwater ponds and marine cage sites is not feasible, there is a need to develop new strategies for the control and prevention of cryptocaryoniasis.
\end{abstract}

KEY WORDS: Cryptocaryon irritans - Characteristics · rDNA sequence - Phylogeny · Variants

\section{INTRODUCTION}

Infection of marine fishes with white spot disease caused by the ciliated protozoan Cryptocaryon irritans is well recorded. Geographical distribution of the disease includes the Indo-Pacific, the Persian Gulf, the Red Sea in Israel, the Atlantic Ocean, and, particularly the Caribbean Sea (Colorni \& Burgess 1997). Recently, the parasite was taxonomically reassigned to the order Prorodontida within the class Prostomatea, and a new family name was recommended, Cryptocaryonidae (Wright \& Colorni 2002). Diverse wild fish and coral reef species are affected by the disease, which sometimes results in mortality (Bunkley-Williams \& Williams 1994, Diggles \& Lester 1996a). Horizontal transfer, dispersal and development of the parasite in coral reefs are facilitated through the low level of host- specificity of C. irritans (Burgess \& Matthews 1995) and the presence of various fish species. In studies investigating the behavior of $C$. irritans, laboratory propagation of the parasite was successfully standardized by Burgess \& Matthews (1994) and by Yoshinaga \& Dickerson (1994) using different host fish species. It is now clear that a broad range of different fish species including temperate marine and tropical freshwater fishes, experimentally adapted to seawater as hosts, that are not affected in their natural habitat can be infected with $C$. irritans because of its low host-specificity (Burgess \& Matthews 1995). Burgess \& Matthews reported that fish species from regions outside the geographical range of $C$. irritans could also serve as hosts to this parasite.

Cryptocaryoniasis in marine fishes is not limited to the natural environment. Cryptocaryon irritans is 
currently becoming an issue of concern in aquaculture because of the high mortality of infected stocks. Colorni (1987) reported that the parasite has become a frequent pest in commercial fish farms, while mortality of about $50 \%$ in tank-cultured juvenile brown spotted grouper Epinephelus tauvina in Kuwait was reported by Rasheed (1989). In Japan, the red sea bream Pagrus major, the tiger puffer Takifugu rubripes and the flounder Paralichthys olivaceus cultured in marine net cages are also susceptible to the disease (Yoshinaga \& Nakazoe 1997, Hirazawa et al. 2001). Infection is likely to be higher in cultured fishes in confinement because of the high stocking density, which favors the probability of a pathogen locating the host. Cryptocaryoniasis in cages, however, is subject to the accessibility of the fish hosts and the aquaculture site to the parasite. Wright \& Colorni (2002) described C. irritans as one of the most devastating parasites affecting marine fishes. Concern regarding the economic effect of C. irritans was previously raised by Matthews et al. (1993) because of the growing ornamental fish industry in Europe and mariculture in tropical and subtropical areas.

In Taiwan, Chao \& Chung (1994) mentioned parasitism by Cryptocaryon irritans of the cultured groupers Epinephelus spp. in the southern area of the island, particularly in Kaoshiung. Most cultured marine fishes in Taiwan are expensive and because of cryptocaryoniasis their culture has been challenged by the spread of the disease and the confidence of farmers dampened.

Since Cryptocaryon irritans can affect a wide range of fish hosts under different conditions, different factors probably influence its infection success. The parasite is exposed to different survival pressures, necessitating its constant adaptation and variation. Diamant et al. (1991) reported mortality of gilt-head sea bream Sparus aurata broodstock due to infection by a Cryptocaryon-like ciliate (distinct from C. irritans) on the Mediterranean coast at an ambient temperature of $22^{\circ} \mathrm{C}$. Variants or strains of C. irritans have also been recognised, based on various parame- ters (Diggles \& Lester 1996a,b,c, Diggles \& Adlard 1997, Jee et al. 2000).

Different strains of parasites have evolved and phylogenetic relationships are used to characterize the various species. Sequencing of ribosomal DNA, particularly the non-coding internal transcribed spacer (ITS)-1 region, is also used to estimate genetic divergence, since some of its regions are highly conserved and therefore useful in discriminating variation within one and the same species. Diggles \& Adlard (1997) determined the nucleotide sequences of the ITS-1 region in various isolates of Cryptocaryon irritans to characterize the species and determine intraspecific variation. Wright \& Colorni (2002), however, sequenced the complete 18s rRNA gene, which resulted in taxonomic re-assignment of the parasite.

This paper describes the developmental characteristics of the different isolates of Cryptocaryon irritans infecting marine fishes in Taiwan. In addition, analyses of the sequences of the amplified regions of $C$. irritans ribosomal DNA are presented.

\section{MATERIALS AND METHODS}

Isolation and culture of Cryptocaryon irritans. Samples of C. irritans-infected fishes were procured from different sources in Taiwan (Table 1) from November 2000 to November 2001. The first C. irritans isolate was obtained from a pair of Chiayi sea bream Sparus sarba, each weighing $300 \mathrm{~g}$, that were sent to our laboratory in the National Taiwan University (NTU), Taipei. The fish were cultured in a pond with a salinity of 5 ppt. The second isolate was originally obtained from cage cultured sea perch Lates calcarifer off the coast of Kaoshiung, and was successfully acclimated and maintained at 10 ppt in the wet laboratory of Kaoshiung Livestock Disease Control Center. A batch of 12th-generation tomonts of C. irritans was then brought to our laboratory for incubation, further culture and analysis. The third isolate was obtained from a grouper, Epinephelus trimaculatus, purchased

Table 1. Cryptocaryon irritans. Sources of isolates in Taiwan

\begin{tabular}{|c|c|c|c|}
\hline Host & Locality & Source & Salinity (ppt) \\
\hline Sparus sarba (sea bream) & Chiayi & Pond & 5 \\
\hline Lates calcarifer (sea perch) & Kaoshiung & $\begin{array}{l}\text { Obtained from 12th-generation } \\
\text { tomonts, but origin was cage }\end{array}$ & n \\
\hline Epinephelus trimaculatus (grouper) & $\begin{array}{l}\text { Purchased from local retailer who } \\
\text { imported the infected fish from Malaysia }\end{array}$ & Wild & 35 \\
\hline Epinephelus coioides (grouper) & Penghu Island & Cage & 35 \\
\hline Melichthys vidua (triggerfish) & Pingtung & Aquarium & 35 \\
\hline
\end{tabular}


from a local fish retailer in Taipei who had imported the infected fish direct from Malaysia. The fourth isolate was from another grouper, E. coioides, cultured in a cage site near Penghu Island and obtained from a fish retailer. The fifth isolate was taken from samples of the triggerfish Melichthys vidua on display at the National Museum of Marine Biology and Aquarium, Pingtung. All originally infected fish samples such as S. sarba, E. trimaculatus, E. coioides, and M. vidua were maintained in our laboratory at NTU.

After its exit from the original host, the parasite was cultured using fingerlings (4 to $6 \mathrm{~cm}$ long) of the grouper Epinephelus coioides as host. About 10 to 15 tomonts each were introduced into moderately aerated 11 beakers with 35 ppt seawater and 1 fish host. The tomonts of the parasite from Chiayi were incubated at a salinity of $7 \mathrm{ppt}$, those from Kaoshiung at a salinity of 10 ppt.

To check whether small tomonts from dead fishes could still produce viable and infective theronts, small tomonts were collected from a beaker containing fish that had not survived the infection and had released small trophonts that developed into small tomonts. Tomonts were also collected from another beaker in which the surviving fish, infected by the same batch of the parasite, released normal trophonts. The trial was conducted by infecting naïve grouper fingerling with 30 small tomonts and another naïve host with 20 normal tomonts. Tomont yield was determined by the formula: Tomont yield $=$ no. of tomonts produced in the succeeding generation/no. of tomonts originally seeded.

Morphological and developmental characteristics of the various stages of the parasite were determined during propagation. Measurements were made with a micrometer.

Sample preparation for histopathology. Samples of infected fish were collected for sectioning and histopathological analysis. Infected samples and aggregating tomonts were collected from 11 beakers and fixed in $10 \%$ neutral-buffered formalin. The skin, fin, and gills were then dissected from fish samples, transferred to an ethyl alcohol series of increasing concentrations for dehydration, infiltrated and embedded in paraffin, and sections (5 $\mu \mathrm{m}$ in thickness) were then stained with hematoxylin and eosin (H\&E). Fixed tomonts were also transferred to ethyl alcohol series for sectioning.

DNA extraction, sequencing and analysis. Except for the Kaoshiung tomonts, first-generation tomonts of all isolates were fixed in $70 \%$ ethanol. The 13 th generation tomonts of the Kaoshiung isolate were fixed in $70 \%$ ethanol. The tomonts were then transferred to $100 \%$ ethanol and stored at $-80^{\circ} \mathrm{C}$ prior to processing. Genomic DNA was extracted following the procedure of Walsh et al. (1991) with slight modification. Briefly, tomonts were transferred to separate Eppendorf tubes and washed 3 times with sterile nannopure water. A volume of water twice that of the tomonts was retained in the Eppendorf tube during the last wash. A sterile needle was used to crush and homogenize the tomonts. The Eppendorf tube was then filled to $1 / 5$ with resin (Bio-Rad 36897 CHELEX 100). Another $100 \mu$ of sterile nannopure water was added to the tube and the sample was further crushed with a micropipette tip. The sample in the tube was then stirred using a vortex mixer at high speed for $12 \mathrm{~s}$ and subsequently warmed in a water bath for $1 \mathrm{~h}$ at $65^{\circ} \mathrm{C}$. After warming, the sample was again crushed with a micropipette tip and heated at $95^{\circ} \mathrm{C}$ for $5 \mathrm{~min}$. The tube was again vortexed at high speed for $12 \mathrm{~s}$. The sample was then centrifuged for $2 \mathrm{~min}$ at $13000 \mathrm{rpm}(14000 \times g)$ after which the supernatant with the extracted DNA was carefully collected from the tube.

Extracted DNA from each of the isolates was amplified using the polymerase chain reaction (PCR, Eppendorf Mastercycler) following the protocol of Diggles \& Adlard (1997). Briefly, double-stranded amplification was performed using Primer 1 (5' GTT CCC CTT GAA CGA GGA ATT C) as forward primer and Primer 2 (5' CGC ATT TCG CTG CGT TCT TC) as reverse primer. Thermal cycling was accomplished with the following program: denaturing at $95^{\circ} \mathrm{C}$ for $60 \mathrm{~s}$, annealing at $55^{\circ} \mathrm{C}$ for $30 \mathrm{~s}$, extension at $72^{\circ} \mathrm{C}$ for $60 \mathrm{~s}$, with a total of 30 cycles. About $5 \mu \mathrm{l}$ of amplified products were electrophoresed through $1.7 \%$ agarose gel in the presence of ethidium bromide. The gel was viewed under an UV light.

Amplified products were purified with a PCR purification kit (PCR-M Clean Up, Viogene-Biotek). Amplified products (100 ng) were used in a cycle-sequencing reaction using dye-nucleotide terminators (ABI PRISM Big Dye Terminator Cycle Sequencing Ready Reaction Kit, Applied Biosystems) and 5 pmol each of Primer 1 and Primer 2 as sequencing primers; sequencing products were purified by the ethanol-precipitation procedure (Applied Biosystems protocol) and sequenced on an ABI PRISM 377-96 Sequencer (Applied Biosystems). Each sample strand was sequenced at least thrice.

Alignment of sequences was done with a Clustal W program (Thompson et al. 1994) with slight manual modifications. A consensus tree was constructed by bootstrap resampling, using the $50 \%$ majority rule of phylogenetic analysis using parsimony (PAUP) 4.0b1 (Swofford 1998). A phylogenetic tree was constructed by the maximum parsimony method, using PAUP 4.0b1 and MEGA Version 2.1 (Kumar et al. 2001). Pairwise comparisons for nucleotide differences, percentage variation and $G+C$ content of the isolates were determined using the DAMBE program for molecular 
analysis (Xia \& Xie 2001). Included in the analysis as reference isolates were sequences of Cryptocaryon irritans strains deposited at GenBank under the following accession numbers and sources: AY029269 (Israel), AY029270 (USA), AY029271 (Australia C), AY029272 (Australia B), and AY029273 (Australia A).
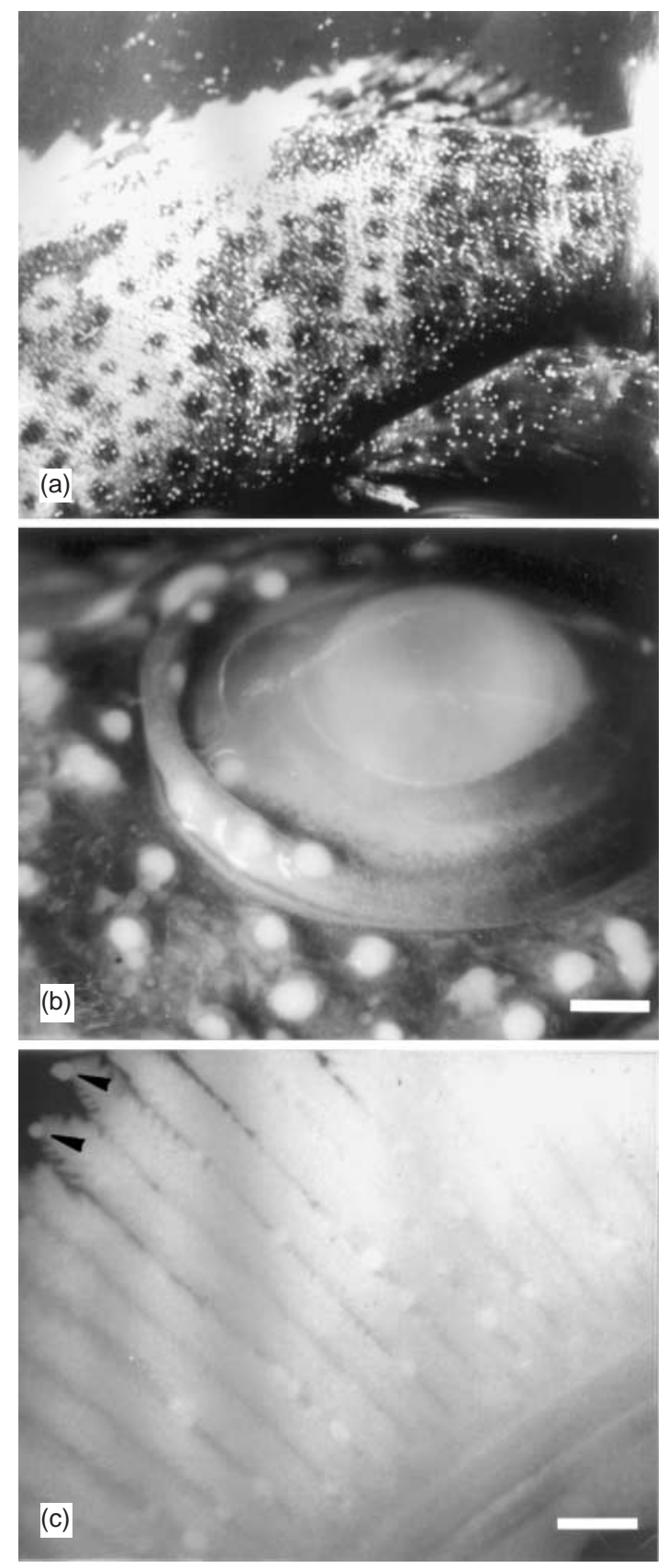

Fig. 1. Cryptocaryon irritans. (a) Heavy infection by trophonts on body of grouper. (b) Trophonts around orbit of the eye of grouper fingerling (scale bar $=1 \mathrm{~mm}$ ). (c) Trophonts encysted between primary lamellae and at lamellar tip (arrowheads in upper left-hand corner); fixed in neutral-buffered formalin; scale bar $=1 \mathrm{~mm}$ )
GenBank accession numbers of isolates. The nucleotide sequences of the isolates from Taiwan described in this paper are registered at GenBank under Accession Nos. AF490381 (Chiayi isolate), AF490382 (Penghu isolate), AF490383 (Kaoshiung isolate), AF490384 (Pingtung isolate), and AF490385 (Malaysia isolate).

\section{RESULTS}

\section{Pathology of infection}

In general, trophonts of all Cryptocaryon irritans isolates were visible as white spots throughout the body and around the eye orbit of host grouper fingerlings during propagation of the parasites (Fig. 1a,b). In the case of the Chiayi isolate, infection was originally manifested only in the gills of the sea bream cultured in a pond, but during the succeeding propagation of the parasite with grouper fingerlings as host, white spots were observed even on the fish body. Trophonts were also seen at the tips of and between the primary lamellae, and on the branchial arch (Fig. 1c). Those enclaved within the base of the secondary lamellae dislodged the affected secondary lamellae layer from the central support structure of the primary lamella.

Invasion of the skin of grouper fingerlings by theronts resulted in encapsulation of the parasite by a single layer of epithelial cells (Fig. 2a). Penetration of the parasite through the layer of scales was not observed in the samples. The presence of 2 or more trophonts (Fig. 2b) in a burrow was noted.

\section{Development characteristics}

Some development characteristics of the different isolates are presented in Table 2. Tomont sizes among the isolates ranged from 290 to $401 \mu \mathrm{m}$. The smallest tomonts $(290 \pm 34 \mu \mathrm{m})$ came from Kaoshiung and the largest $(401 \pm 39 \mu \mathrm{m})$ from Penghu. The size of the Penghu tomonts was significantly different from that of the other isolates (Tukey's HSD test, $\alpha=0.05$ ). The duration of the life cycle of the parasite ranged from 6 to $18 \mathrm{~d}$, the last day being considered that on which no white spot was evident on the body of the host fish.

Some tomonts had a constriction at their center, but no dividing walls were observed (Fig. 3a). Tomonts of most isolates adhered to the bottom of the beaker. The first and second generations of the Penghu tomonts exhibited non-adherence or weak adherence to the bottom of the beaker. The third generation and the succeeding generations were however able to adhere to the bottom of the culture vessels. The ability of the 


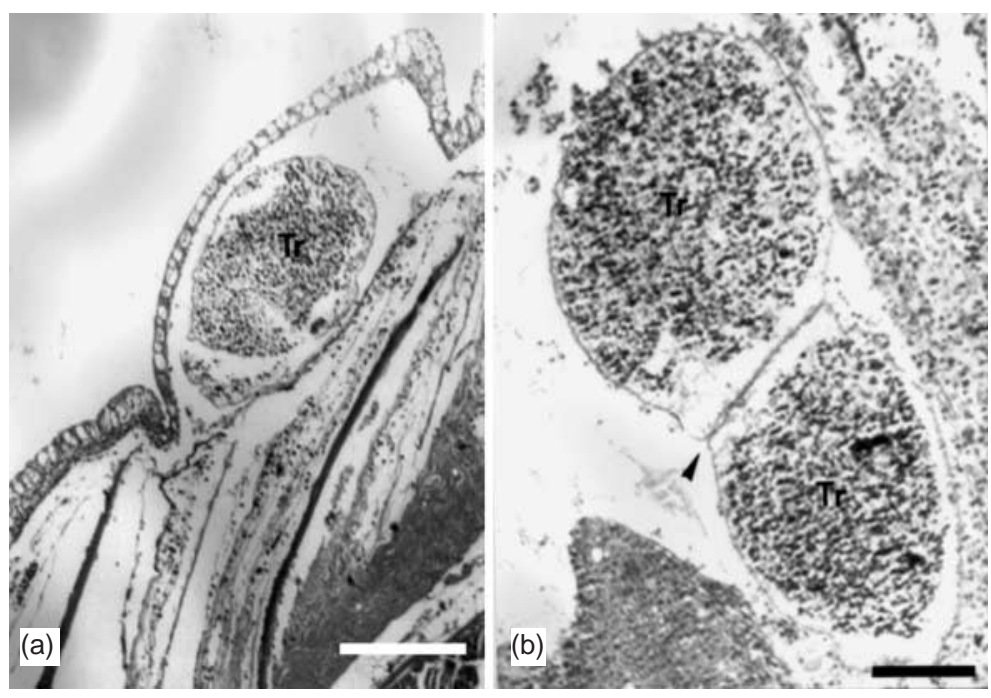

Fig. 2. Cryptocaryon irritans. (a) Cross-section of skin of grouper fingerling showing single layer of epithelial cells encapsulating a trophont ( $\operatorname{Tr}$ ) (scale bar $=200 \mu m_{i}$ H\&E). (b) Sagittal section of caudal fin showing 2 trophonts (Tr) with fused cell wall occupying a burrow (arrowhead) (scale bar $=100 \mu m_{i}$ H\&E)

albeit a low tomont yield was obtained. The mean size of premature tomonts was $210 \pm 42 \mu \mathrm{m}(\mathrm{n}=10)$, while the mean size of mature tomonts of the same generation but from a different batch was $333 \pm 37 \mu \mathrm{m}(\mathrm{n}=$ 10). Statistical analyses (Zar 1999) revealed significant differences in size between premature and mature tomonts (1-tailed 2 sample Student's t-test, p < 0.05). Tomont yields were 3.88 (mean of 2 replicates) and 62.5 (mean of 2 replicates) for premature and mature tomonts, respectively.

\section{Sequence characteristics and analyses}

Nucleotide sequences of the amplified regions of the different Cryptocaryon irritans isolates from Taiwan and from GenBank consisted of 320 or 321 bases of rDNA (Fig. 5). These were composed of

tomonts to form aggregates or 'carpets' (Fig. 3b) also changed. The Penghu and Malaysian tomonts were present as individuals at first, but became capable of forming aggregates in the fifth generation and fourth generation, respectively, and in all succeeding generations. The Chiayi tomonts were also aggregate-forming on the bottom of the beaker. The Kaoshiung and Pingtung isolates had aggregate-forming tomonts from the beginning of propagation. Tomonts in the size range $255 \pm 25 \mu \mathrm{m}(\mathrm{n}=50)$ were able to produce 195 to 305 theronts (Fig. 4a) per tomont. A number of theronts in a batch were observed to have constrictions (Fig. 4b,c).

Our attempt to produce succeeding generation of tomonts from premature and small fourth-generation tomonts developed from dead fishes was successful,
137 bases from the 3 ' end of the $18 \mathrm{~S}$ region, 169 or 170 bases from the entire ITS-1 region and 14 bases from the $5.8 \mathrm{~S}$ region. The sequence of the isolate from Pingtung was identical to that of the USA isolate (Fig. 5, Table 3). Likewise, both isolates from Malaysia and Israel had identical sequences.

Differences in the nucleotides were revealed in 33 positions in the amplified regions of the sequences (Fig. 5). Alignment gaps were present in Base Positions 200 and 201 for the Chiayi and Australia A isolates and the Kaoshiung and Penghu isolates, respectively. One nucleotide difference was noted in the 47 th base position in the $18 \mathrm{~S}$ region. The ITS-1 region had nucleotide differences in 28 base positions, whereas differences in 4 positions were observed in the amplified

Table 2. Cryptocaryon irritans. Some development characteristics of isolates from Taiwan, including isolate from live fish imported from Malaysia (temperature range 20 to $23^{\circ} \mathrm{C}$ ). Statistical analysis of tomont size used ANOVA and Tukey's HSD test (Zar 1999). Tomont sizes with different superscripts are significantly different $(\alpha=0.05)$

\begin{tabular}{|c|c|c|c|c|}
\hline Isolate & $\begin{array}{l}\text { Tomont size } \\
(\mu \mathrm{m})(\mathrm{n}=20)\end{array}$ & $\begin{array}{l}\text { Duration of } \\
\text { life cycle (d) }\end{array}$ & $\begin{array}{l}\text { Attachment of tomonts to bottom } \\
\text { of culture vessel }\end{array}$ & $\begin{array}{l}\text { Formation of tomonts on bottom } \\
\text { of culture vessel }\end{array}$ \\
\hline Penghu Island & $401 \pm 39^{a}$ & $8-11$ & $\begin{array}{l}\text { Non-adherent to weakly adherent at } \\
\text { 1st generation, adherent at 3rd } \\
\text { generation and thereafter }\end{array}$ & $\begin{array}{l}\text { Individual in } 1 \text { st generation, form } \\
\text { aggregates at } 5 \text { th generation and } \\
\text { thereafter }\end{array}$ \\
\hline Pingtung & $324 \pm 35^{\mathrm{b}}$ & $10-16$ & Adherent & Form aggregates \\
\hline Malaysia & $317 \pm 33^{\mathrm{b}}$ & $7-18$ & Adherent & $\begin{array}{l}\text { Individual in } 1 \text { st generation, form } \\
\text { aggregates at } 4 \text { th generation and } \\
\text { thereafter }\end{array}$ \\
\hline Chiayi & $310 \pm 61^{b}$ & $7-18$ & Strongly adherent & $\begin{array}{l}\text { Individual, capable of forming } \\
\text { aggregates in beaker }\end{array}$ \\
\hline Kaoshiung & $290 \pm 34^{b}$ & $6-12$ & Strongly adherent & Form aggregates \\
\hline
\end{tabular}




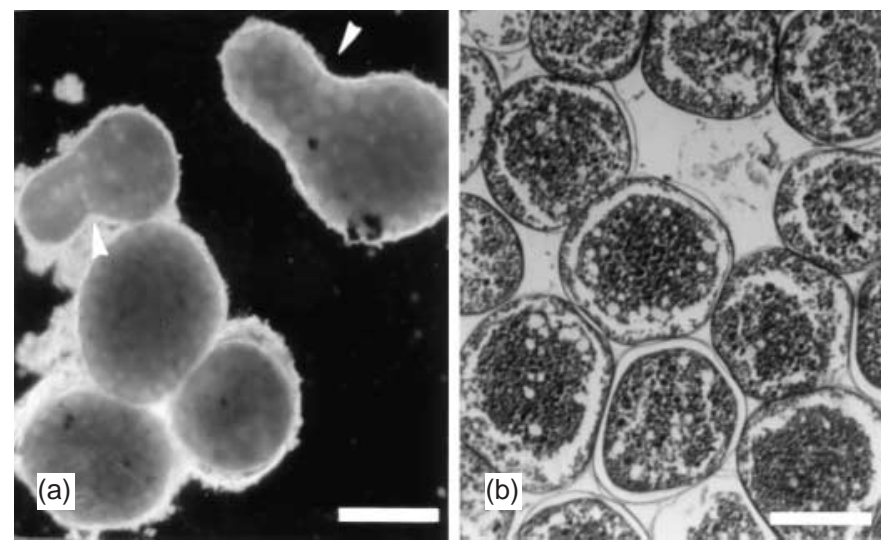

Fig. 3. Cryptocaryon irritans. (a) Live tomont aggregate; 2 tomonts display constriction (arrowheads) near center. (b) Cross-section of tomont aggregate (carpet) with fused cyst walls between tomonts (scale bar $=200 \mu m_{;}$H\&E)
Heron Island (Australian $\mathrm{C}$ isolate) and Moreton Bay (Australian B isolate), with a bootstrap support of $85 \%$.

\section{DISCUSSION}

The fusion of the secondary lamellae and the presence of hyperplastic epithelial cells in the branchial tissues of the host fishes were due to the invasion of Cryptocaryon irritans. These were pathological results of the infection. The parasites settle within narrow epithelial enclaves, in extended tunnels burrowed in the epithelium, or in the basement membrane of the gill filament (Diamant et al. 1991, Colorni \& Burgess 1997, Jee et al. 2000). In the present study, some trophonts
5.8 $\mathrm{S}$ region. The $\mathrm{G}+\mathrm{C}$ content of the ITS-1 region varied among the Taiwan and Malaysian isolates. The percentage $\mathrm{G}+\mathrm{C}$ were $20.71 \%$ (Chiayi isolate), $21.76 \%$ (Pingtung and Malaysian isolates) and $23.67 \%$ (Penghu and Kaoshiung isolates).

Nucleotide differences and percentage variation between isolates showed that Cryptocaryon irritans from Kaoshiung (4.73 to $12.43 \%$ ) and Penghu (4.73 to $9.47 \%$ ) were the 2 most aberrant among the isolates when compared pairwise to the others (Table 3). The Kaoshiung isolate varied by $4.73 \%$ from the Penghu isolate, while $C$. irritans from Pingtung was identical to the isolate from the USA and its sequence was close to the Malaysian and Israel isolates, with only $0.59 \%$ variation. The parasite from Malaysia was identical to the Israel isolate and close to the USA isolate, likewise with only $0.59 \%$ variation. C. irritans from Chiayi was closest to the Australia A isolate, also with $0.59 \%$ variation.

PAUP analysis of nucleotide sequences of the different isolates (particularly the bootstrap resampling, which produced similar results to the maximum parsimony method) revealed different groups of Cryptocaryon irritans from Taiwan (Fig. 6). The maximum parsimony method with the bootstrap consensus using MEGA2 produced values of CI (consistency index) = 0.8948, RI (retention index) $=0.8788$, and RCI $($ rescaled consistency index) $=0.7863$. Most of the isolates comprising the major group consisted of 2 subgroups with a bootstrap value of $55 \%$, while the Chiayi and the Australian A isolates were grouped separately from the others. The parasite isolates from Kaoshiung and Penghu comprised a subgroup of the major group, with a $100 \%$ bootstrap value. Another subgroup was comprised of $C$. irritans isolates from Pingtung and Malaysia together with isolates from Israel, USA,
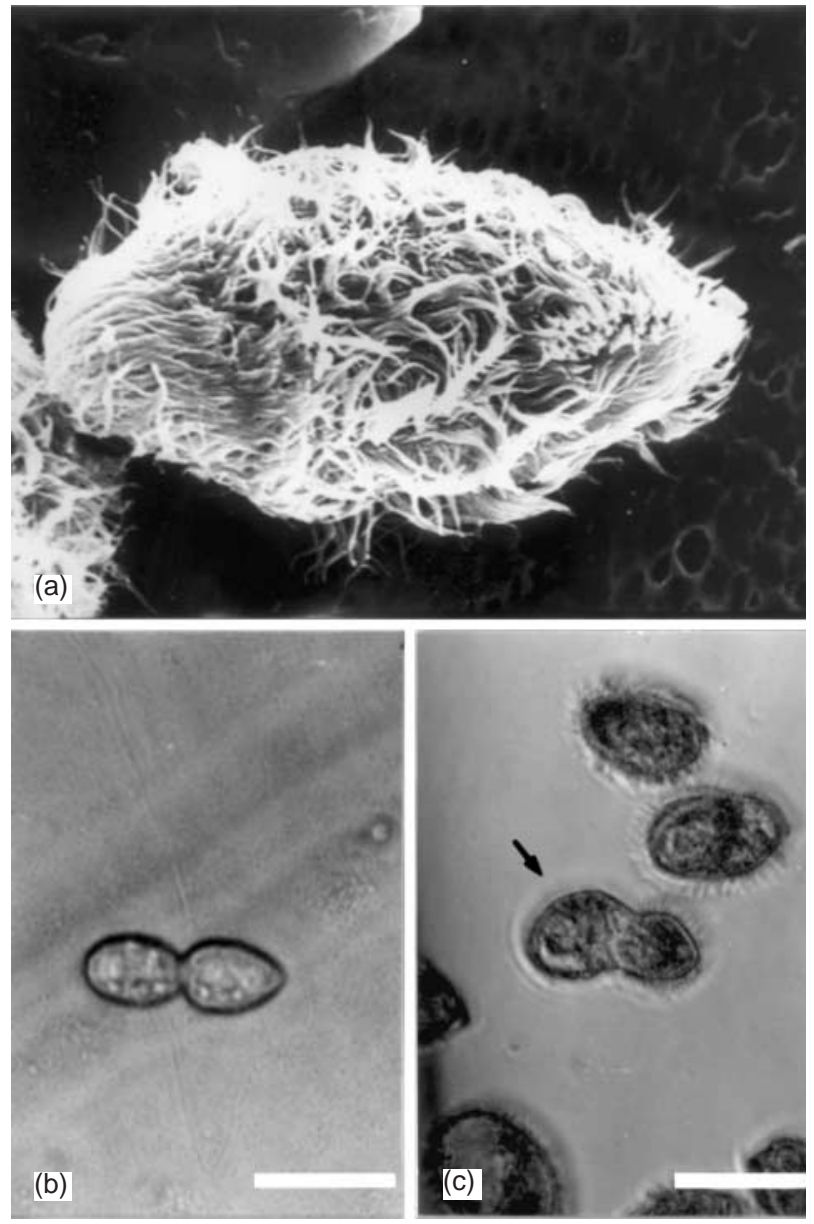

Fig. 4. Cryptocaryon irritans. (a) Scanning electron micrograph of newly emerged Kaoshiung theront (1750× magnification). (b) Swimming theront with constriction and septumlike division (scale bar $=50 \mu \mathrm{m}$ ). (c) Alcohol-fixed theronts; 1 theront (arrow) displays constriction at center of body (scale bar $=70 \mu \mathrm{m})$ 
$18 \mathrm{~S}$

Aus. A CTACCGATtTCGAGTGATCCGGTGAACCTTCTGGACTGCGCTAACACTAGTTAGTGCGGGAAGTTAAGTAAACCACTTCACTTAGAGGAAGGAGAAGTCGTAACAAGGTTTCCGTAGGTG 120

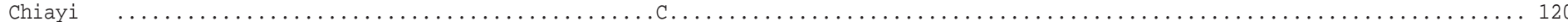

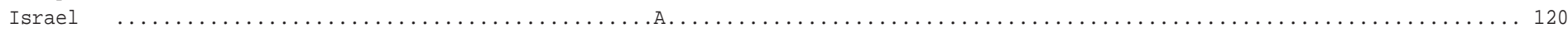

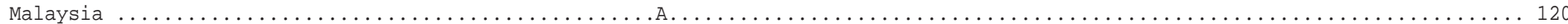

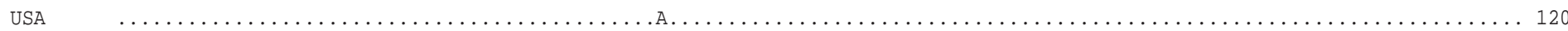

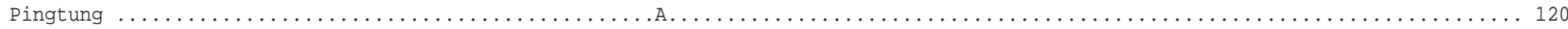

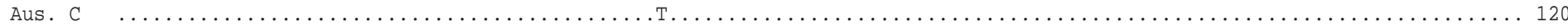

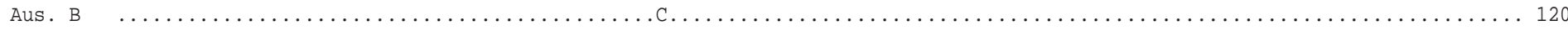

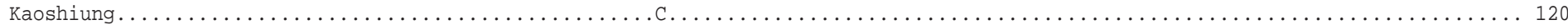

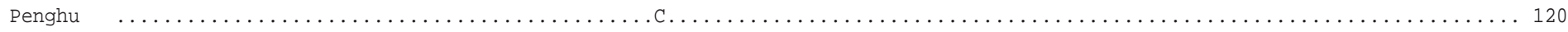
$18 \mathrm{~S} \quad \rightarrow \leftarrow \quad$ ITS-1

Aus. A AACCTGCGGAAGGATCATTAACACAATTAAGATCAAACCTAAAAATTTATTCTGATGTATTGAGATCTGATAATtTTTAATTATCAATCTCAAATtTTTACAAATTTATTTTAATAATA 239

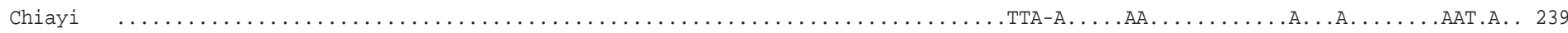

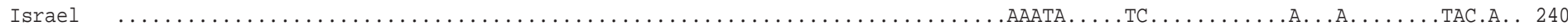

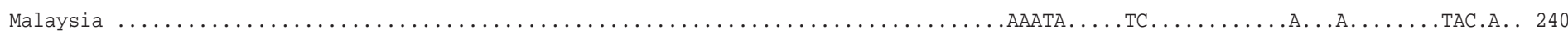

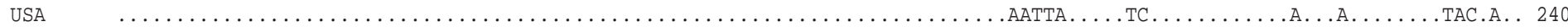

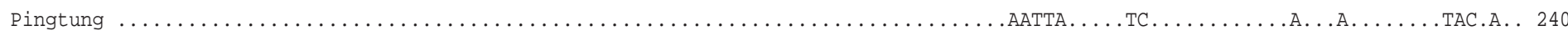

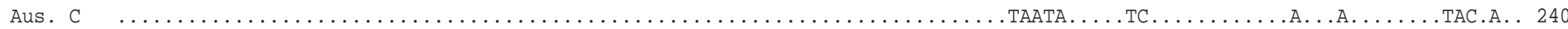

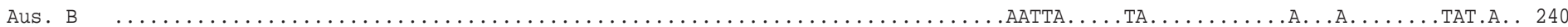

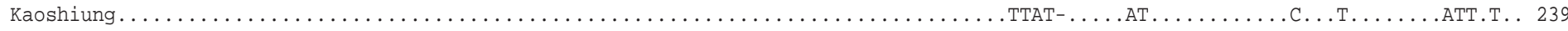

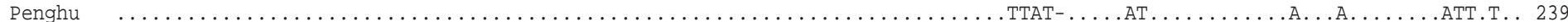

Aus. A Chiayi

Israel Malaysia USA

Pingtung

Aus. C

Aus. B

Kaoshiung

Penghu

$$
\text { ITS-1 } \rightarrow \leftarrow 5.8 \mathrm{~S}
$$

AATATCATTAAGTTAATTAAATTAACTAAAGAAAATTTTCAACGGTGGATATCTTGGCTCCCATAACGATGAAGAACGCAG 320

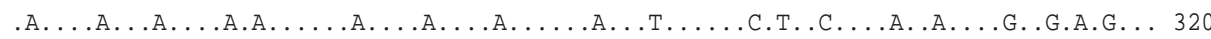

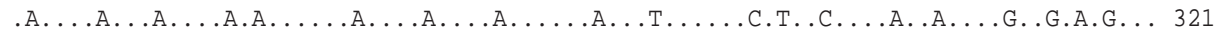

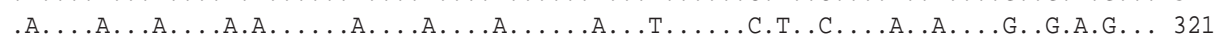

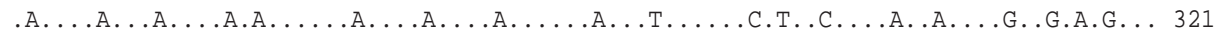

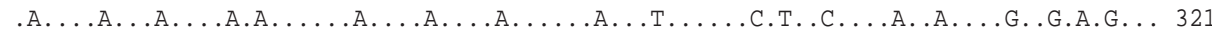

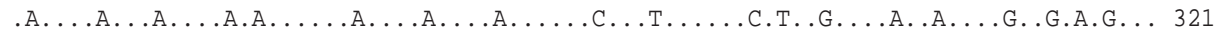

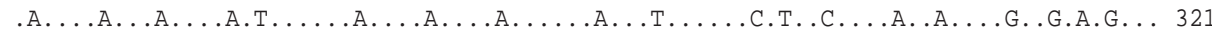

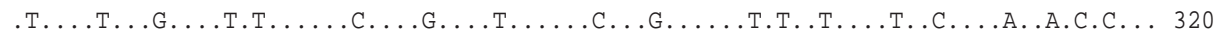

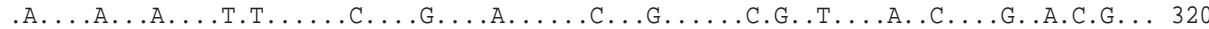

Fig. 5. Cryptocaryon irritans. Alignment of nucleotide sequences of amplified regions of isolates consisting of part of $18 \mathrm{~S}$, entire ITS-1, and part of 5.8 S. Included for comparison were C. irritans sequences from GenBank with Accession Nos. AY029269 (Israel), AY029270 (USA), AY029271 (Heron Island, Australia: Aus. C), AY029272 (Moreton Bay, Australia: Aus. B), and AY029273 (Australia: Aus. A). (. : identical bases; -: alignment gap)

Table 3. Cryptocaryon irritans. Pairwise comparisons of nucleotide differences (below diagonal) and percentage variation (above diagonal) in amplified ITS-1 region of the different isolates. Aus.: Australia; T: Taiwan

\begin{tabular}{|c|c|c|c|c|c|c|c|c|c|c|}
\hline Isolates & Chiayi & Pingtung & Kaoshiung & Penghu & Malaysia & Aus. A & Aus. B & Aus. C & USA & Israel \\
\hline Chiayi (T) & & 2.94 & 10.06 & 6.51 & 3.53 & 0.59 & 2.37 & 3.55 & 2.96 & 3.55 \\
\hline Pingtung (T) & 5 & & 12.43 & 8.88 & 0.59 & 3.53 & 1.76 & 2.35 & 0 & 0.59 \\
\hline Kaoshiung (T) & 17 & 21 & & 4.73 & 12.94 & 9.47 & 11.24 & 11.83 & 12.43 & 13.02 \\
\hline Penghu $(\mathrm{T})$ & 11 & 15 & 8 & & 9.41 & 5.92 & 7.69 & 8.28 & 8.88 & 9.47 \\
\hline Malaysia & 6 & 1 & 22 & 16 & & 4.12 & 2.35 & 1.18 & 0.59 & 0 \\
\hline Aus. A & 1 & 6 & 16 & 10 & 7 & & 1.76 & 4.12 & 3.53 & 4.12 \\
\hline Aus. B & 4 & 3 & 19 & 13 & 4 & 3 & & 3.53 & 1.76 & 2.35 \\
\hline Aus. C & 6 & 4 & 20 & 14 & 2 & 7 & 6 & & 1.76 & 1.18 \\
\hline USA & 5 & 0 & 21 & 15 & 1 & 6 & 3 & 3 & & 0.59 \\
\hline Israel & 6 & 1 & 22 & 16 & 0 & 7 & 4 & 2 & 1 & $x^{2}$ \\
\hline
\end{tabular}

were observed to have burrowed at the base of the secondary lamella layer (thereby 'lifting' this) and in the branchial arch. In addition, trophonts were observed to have lodged between the primary lamellae and even at their tips. In the skin of the host grouper fingerling, the trophonts did not penetrate the scale layer and were encapsulated by the outermost single layer of epithelial cells; this increases the development success of the trophonts and the virulence of the parasite, since invasion by theronts and eventual establishment of trophonts can occur with relative ease. 


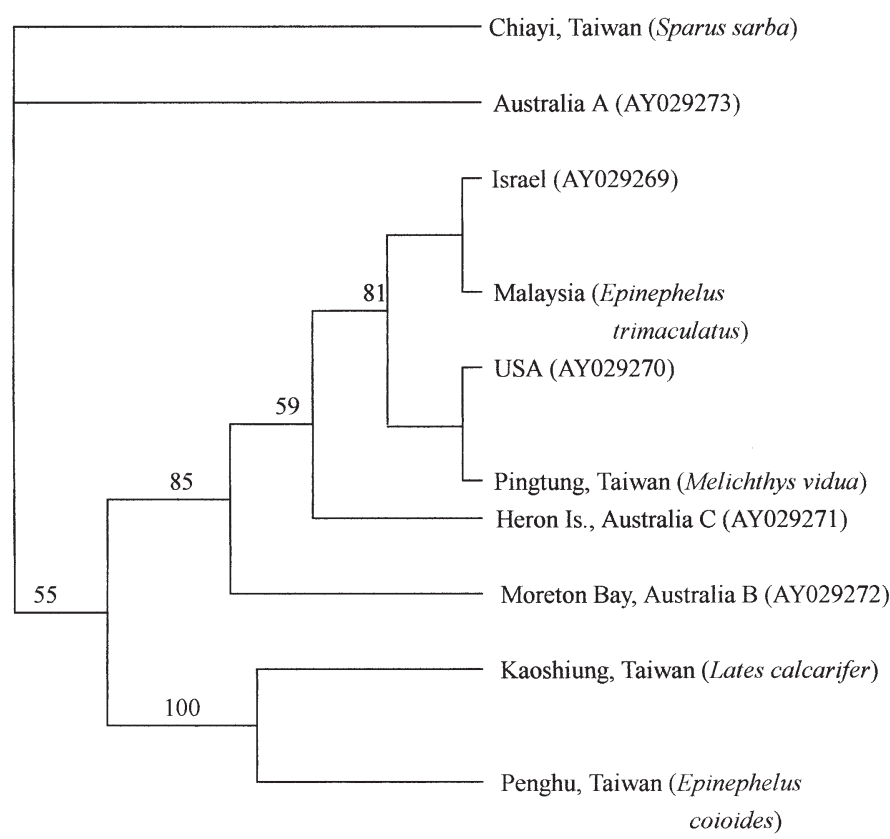

Fig. 6. Cryptocaryon irritans. Bootstrap resampling of $50 \%$ majority-rule consensus tree generated by PAUP on sequences of amplified regions of rDNA of various isolates, showing geographical sources of isolates, including those from GenBank, with corresponding accession number of the parasite rDNA sequence or the fish host of the parasite. (Note: Pingtung isolate is identical to USA isolate and Malaysian isolate is identical to Israel isolate)

Production of daughter tomonts by budding was reported by Jee et al. (2000). In the present study, we observed that the presence of tomonts with constrictions and apparent 'budding' did not result in the formation of a new cyst wall and complete separation despite the division of cells inside the cyst. Theronts, however, exited from the cysts. Constrictions were apparently the result of pressure on the sides of the aggregating tomonts.

Small trophonts that exited prematurely from dead fish were still capable of causing infection of other fish, although the tomont yield was much lower. Colorni (1985) suggested that trophonts that exited prematurely from a fish when it dies would not be able to infect another host fish. In this respect, selection of tomonts for continuous propagation should consider size, although small tomonts produced from dead fish can still infect a fish host at a lower intensity and produce mature and normal tomonts.

The $100 \%$ similarity in sequences of Cryptocaryon irritans particularly between Pingtung and USA isolates and between Malaysian and Israel isolates recorded in the present study, has no explanation at the moment. Diggles \& Adlard (1997) did not encounter $100 \%$ similarity in their isolates obtained from differ- ent geographical sources. In a study by Andree et al. (1999) on various isolates of the myxosporean parasite Myxobolus cerebralis from different geographical sources, the sequences of the amplified $18 \mathrm{~S}$ region in the rDNA were nearly identical, while the ITS-1 region sequences were completely so. These similarities in the nucleotide sequences arose from the transport of the parasite from one geographical area to another. In the fungus Cenococcum geophilum, sequence similarities among different geographical isolates were explained as a product of dispersal by wind, water, and various animals, including import and export of materials by humans (Shihohara et al. 1999).

Taiwan isolates have more nucleotide differences at 33 base positions than the isolates of Diggles \& Adlard (1997), in which a sequence divergence was evident at only 12 positions. Based on the rDNA sequences of the amplified regions, Cryptocaryon irritans from Taiwan and Malaysia were distinct from each other. The isolates from Diggles \& Adlard (1997) were obtained from warm and cold waters of different geographically distant sources. The sequences of $C$. irritans isolates from Penghu and Kaoshiung were the only sequences with significant bootstrap support (100\%), and both isolates had an identical G + C content of $23.67 \%$, the highest among the isolates. Ironically, the Penghu and Kaoshiung isolates were the largest and smallest, respectively, in terms of tomont diameter. This means that morphology, i.e. tomont size, does not always support phylogeny based on the rDNA sequence, nor are developmental characteristics always consistent with molecular relationships (Elbadri et al. 2002). Hence, as suggested by Thompson \& Lymbery (1990), phenotypic variation in some parasites does not always appear to have a genetic basis. On the other hand, Diggles \& Adlard (1997) reported that morphological variation might not be distinguishable between isolates that were genetically distinct, and that laboratory propagation and repeated passage of $C$. irritans could result in greater variation in the sequence compared to the original isolate. C. irritans from Kaoshiung had been propagated in the laboratory for about 12 generations before sequencing was performed. This fact and adaptation to lower salinity could have added to the genetic divergence of the Kaoshiung isolate, which was the most aberrant (compared pairwise) based on its nucleotide percentage variation (4.73 to $13.02 \%$ ). It must be added, however, that the Penghu isolate also displayed a high percentage of variation (4.73 to $9.47 \%$ ), despite the fact that sequencing was performed on its first-generation tomonts.

Pairwise comparisons revealed high percentage variation (0.59 to $13.02 \%)$ among the Taiwan isolates, indicating high intraspecific diversity, consistent with the general high biodiversity in this country. Percent- 
age variation among the Taiwan isolates was higher than among the isolates of Diggles \& Adlard (1997). Taiwan is a small island, bounded on all sides by oceanic and sea waters, and with a tropical and subtropical climate. Various currents influence the surrounding waters, facilitating the migration and interaction of marine fishes. Hence, the structure of marine life is expected to be dynamic.

The phylogenetic tree in Diggles \& Adlard (1997) comprised 2 groups, the first consisting of Israel, Heron and USA isolates, the second of Australian isolates. The phylogeny of the isolates in the present study appeared to be in agreement with the groups in Diggles \& Adlard (1997). Forming a major group (with 2 subgroups) and corresponding to the first group of Diggles \& Adlard (1997) were Cryptocaryon irritans from Pingtung and Malaysia as one subgroup and the highly aberrant $C$. irritans from Kaoshiung and Penghu as the second subgroup. The low-salinity variant from Chiayi was not included in the major group. The phylogeny suggests that $C$. irritans is grouped on the basis of salinity tolerance, with low-salinity and marine variants. The subgrouping of the major group revealed the existence of highly aberrant isolates differing from the other variants.

Diggles \& Adlard (1997) further described 4 strains in their study, with 1 strain composed of the Australia isolates, based on development and morphological and genetic characteristics. Along this line, each of the Taiwan isolates is unique on the basis of genetic and developmental (or morphological) characteristics. Cryptocaryon irritans from Taiwan has therefore further widened the diversity of the species presented in the study of Diggles \& Adlard (1997).

Classifying Cryptocaryon irritans as a distinct isolate or strain on the basis of certain development parameters has been suggested (Diamant et al. 1991, Diggles \& Adlard 1997, Jee et al. 2000). For example, Diamant et al. (1991) described a seemingly distinct isolate that, when the gills were severely infected, could also infect the skin and eyes that had individual and weakly adherent tomonts and trophonts in extended tunnels burrowed in the epithelium. In the present study, changes in some development features of tomonts were noted after only a few generations, such as from individual to aggregate-forming tomonts and from non-adherent or weakly adherent to adherent tomonts. These changes may be attributable to the selection of certain genetic variants to enable the survival of the parasite. Adherent and aggregating capabilities can help the tomonts to survive the abrasive effect of water movement under natural conditions. The Chiayi isolate at first infected only the gills of cultured sea bream, and the infection was considered heavy because of significant fish mortality in the pond.
However, when the Chiayi parasite was propagated, it infected the skin as well as the gills of the host, regardless of the intensity of the infection. Therefore, classifying strains of the Taiwan isolates on the basis on these parameters is not feasible. The Taiwan isolates are highly aberrant and divergent members of the same species, as described by Elbadri et al. (2002) for the parasitic nematode Radopholus similis.

In controlled confinement, Cryptocaryon irritans can be controlled by changing the salinity of the water (Colorni 1987, Rigos et al. 2001). Cheung et al. (1979) likewise noted that lower salinity has an adverse effect on the development of this parasite. Salinity can, however, only be lowered when the water and the cultured fishes can be easily manipulated and controlled. The occurrence of cryptocaryoniasis in inland sea bream ponds in Chiayi with a salinity of 5 pt resulted in daily mortality of the cultured fish (about 20 dead fish $\mathrm{d}^{-1}$, each weighing ca. $300 \mathrm{~g}$ ). This is the first record of outbreak of $C$. irritans at such a low recorded salinity in aquaculture conditions. Diggles \& Adlard (1997), however, cited an unpublished report related to survival of tomonts below $10 \mathrm{ppt}$, and Diggles \& Lester (1996a) suggested an extended distribution of $C$. irritans in estuaries. The successful adaptation and continuous propagation of the Kaoshiung isolate at $10 \mathrm{ppt}$ further attests to the need for immediate attention to outbreaks of the parasite at low salinity. It suggests that $C$. irritans is capable of adapting successfully to lower salinities and thus of causing damage over a wider salinity range, including brackishwater. Application of osmotic shock to damage the tomonts, such as hyposalinity treatment for marine species and hypersalinity for low-salinity variants, is not feasible for marine cage sites and inland brackishwater ponds, where freshwater and seawater, respectively, are not readily available. Other forms of treatment, curative or preventive, appropriate for marine cage culture and inland ponds are required. Developing the resistance of fish to cryptocaryoniasis is another aspect that needs to be explored.

The present study has described some developmental and genetic characteristics of Cryptocaryon irritans in marine fishes, mostly cultured species, in Taiwan. $C$. irritans is able to shift its developmental characteristics. rDNA sequences of the amplified regions of the Taiwan isolates revealed a wide range in percentage variation, suggesting high intraspecific biodiversity. $C$. irritans from Pingtung and the USA had identical nucleotide sequences and the Malaysian and Israel isolates were identical. Analysis revealed the presence of highly aberrant $C$. irritans isolates in Taiwan and a low-salinity variant. The results indicate that the range of salinity tolerated by the parasite is becoming alarmingly wider. 
Acknowledgements. The authors sincerely thank Mr. ChiaBen Chao of Kaoshiung Livestock Disease Control Center, Fengshan, Taiwan, for sharing information, experience and Kaoshiung parasite picture (Fig. 4a) and tomonts; Dr. LeeShing Fang and Mr. Robert Chang from the National Museum of Marine Biology and Aquarium, Pingtung, Taiwan, for providing infected triggerfishes; Mr. Jie-Ling Lee from the Pingtung Livestock Diseases Control Center, Pingtung, Taiwan, for sending infected seabream samples; Mr. Mao-Yen Chen and Dr. San-San Tsay from the Department of Botany, National Taiwan University, for assisting in the molecular techniques; and Ms. Meng-Shin Shiao and Dr. Alex Hon-Sen Yu from the Department of Zoology, National Taiwan University, for phylogenetic analysis of the different parasite isolates. The Council of Agriculture, Republic of China, provided funding support for this research under Grant No. 91AS1.4.5-FA-F3(13). Nucleotide sequence data reported in this paper are available in the GenBank under Accession Nos. AF 490381, AF490382, AF490383, AF490384, and AF490385.

\section{LITERATURE CITED}

Andree KB, El-Matbouli M, Hoffman RW, Hedrick RP (1999) Comparison of 18S and ITS-1 rDNA sequences of selected geographic isolates of Myxobolus cerebralis. Int J Parasitol 29:771-775

Bunkley-Williams L, Williams EH Jr (1994) Diseases caused by Trichodina spheroidesis and Cryptocaryon irritans (Ciliophora) in wild coral reef fishes. J Aquat Anim Health 6: 360-361

Burgess PJ, Matthews RA (1994) A standardized method for the in vivo maintenance of Cryptocaryon irritans (Ciliophora) using the grey mullet Chelon labrosus as an experimental host. J Parasitol 80:288-292

Burgess PJ, Matthews RA (1995) Fish host range of seven isolates of Cryptocaryon irritans (Ciliophora). J Fish Biol 46: $727-729$

Chao CB, Chung HY (1994) Study on Cryptocaryon irritans infection on captive grouper (Epinephelus spp.), lifecycle and pathogenicity. Council of Agriculture Fisheries Series No. 46, Fish Dis Res 14:31-40 (in Chinese with Chinese and English summaries)

Cheung PJ, Nigrelli RF, Ruggieri GD (1979) Studies on cryptocaryoniasis in marine fish: effect of temperature and salinity on the reproductive cycle of Cryptocaryon irritans Brown, 1951. J Fish Dis 2:93-97

Colorni A (1985) Aspects of the biology of Cryptocaryon irritans, and hyposalinity as a control measure in cultured gilt-head sea bream Sparus aurata. Dis Aquat Org 1:19-22

Colorni A (1987) Biology of Cryptocaryon irritans and strategies for its control. Aquaculture 67:236-237

Colorni A, Burgess PJ (1997) Cryptocaryon irritans Brown 1951, the cause of white spot disease in marine fish: an update. Aquar Sci Conserv 1:217-238

Diamant A, Issar G, Colorni A, Paperna I (1991) A pathogenic Cryptocaryon-like ciliate from the Mediterranean Sea. Bull Eur Assoc Fish Pathol 11:122-124

Diggles BJ, Adlard RD (1997) Intraspecific variation in Cryptocaryon irritans. J Eukaryot Microbiol 44:25-32

Diggles BJ, Lester RJG (1996a) Infections of Cryptocaryon irritans on wild fish from southeast Queensland, Australia. Dis Aquat Org 25:159-167

Editorial responsibility: Wolfgang Körting,

Hannover, Germany
Diggles BJ, Lester RJG (1996b) Influence of temperature and host species on the development of Cryptocaryon irritans. J Parasitol 82:45-51

Diggles BJ, Lester RJG (1996c) Variation in the development of two isolates of Cryptocaryon irritans. J Parasitol 82: 384-388

Elbadri GAA, De Ley P, Waeyenberge L, Vierstraete A, Moens M, Vanfleteren J (2002) Intraspecific variation in Radopholus similis isolates assessed with restriction fragment length polymorphism and DNA sequencing of the internal transcribed spacer region of the ribosomal RNA cistron. Int J Parasitol 32:199-205

Hirazawa N, Oshima S, Hara T, Mitsuboshi T, Hata K (2001) Antiparasitic effect of medium-chain fatty acids against the ciliate Cryptocaryon irritans infestation in the red sea bream Pagrus major. Aquaculture 198:219-228

Jee BY, Kim KH, Park SI, Kim YC (2000) A new strain of Cryptocaryon irritans from the cultured olive flounder Paralichthys olivaceus. Dis Aquat Org 43:211-215

Kumar S, Tamura K, Jakobsen IB, Nei M (2001) MEGA2: molecular evolutionary genetics analysis software. Arizona State University, Tempe

Matthews BF, Matthews RA, Burgess PJ (1993) Cryptocaryon irritans Brown, 1951 (Ichthyophthiriidae): the ultrastructure of the somatic cortex throughout the life cycle. J Fish Dis 16:339-349

Rasheed VM (1989) Diseases of cultured brown-spotted grouper Epinephelus tauvina and silvery black porgy Acanthopagrus cuvieri in Kuwait. J Aquat Anim Health 1: 102-107

Rigos G, Pavlidis M, Divinach P (2001) Host susceptibility to Cryptocaryon sp. infection of Mediterranean marine broodfish held under intensive culture conditions: a case report. Bull Eur Assoc Fish Pathol 21:33-36

Shihohara ML, LoBuglio KF, Rogers SO (1999) Comparison of ribosomal DNA ITS regions among geographic isolates of Cenococcum geophilum. Curr Genet 35:527-535

Swofford DL (1998) PAUP: phylogenetic analysis using parsimony, Version 4.0b1. Sinauer, Sunderland, MA

Thompson JD, Higgins DG, Gibson TJ (1994) CLUSTAL W: improving the sensitivity of progressive multiple sequence alignment through sequence weighting, position-specific gap penalties and weight matrix choice. Nucleic Acids Res 22:4673-4680

Thompson RCA, Lymbery AJ (1990) Intraspecific variation in parasites - What is a strain? Parasitol Today 6:345-348

Walsh PS, Metzger DA, Higuchi R (1991) Chelex 100 as medium for simple extraction of DNA for PCR-based typing from forensic material. Biotechniques 10:506-513

Wright ADG, Colorni A (2002) Taxonomic re-assignment of Cryptocaryon irritans, a marine fish parasite. Eur J Protistol 37:375-378

Xia X, Xie Z (2001) DAMBE: data analysis in molecular biology and evolution. J Hered 92:371-373

Yoshinaga T, Dickerson HW (1994) Laboratory propagation of Cryptocaryon irritans on saltwater-adapted Poecilia hybrid, the black molly. J Aquat Anim Health 6:197-201

Yoshinaga T, Nakazoe J (1997) Acquired protection and production of immobilization antibody against Cryptocaryon irritans (Ciliophora, Hymenostomatida) in mummichog (Fundulus heteroclitus). Fish Pathol 32:229-230

Zar JH (1999) Biostatistical analysis, 4th edn. Prentice-Hall, Upper Saddle River, NJ

Submitted: May 2, 2002; Accepted: October 30, 2002

Proofs received from author(s): March 18, 2003 